\title{
Nasopalatine Canal Revisited: An Insight to Anterior Maxillary Implants
}

\author{
Atul Anand Bajoria1 ${ }^{*}$, Tripti Kochar ${ }^{1}$, N. C. Sangamesh' ${ }^{1}$, Silpiranjan Mishra', Purnendu Rout ${ }^{1}$, \\ Abhay Sonthalia ${ }^{2}$
}

${ }^{1}$ Department of Oral Medicine and Radiology, Kalinga Institute of Dental Sciences KIIT University, Bhubaneswar, India ${ }^{2}$ Department of Prosthodontics, Awadh Dental College and Hospital, Jamshedpur, India

Email: *atultink@gmail.com

How to cite this paper: Bajoria, A.A., Kochar, T., Sangamesh, N.C., Mishra, S., Rout, P. and Sonthalia, A. (2018) Nasopalatine Canal Revisited: An Insight to Anterior Maxillary Implants. Open Journal of Stomatology, 8, 1-15.

https://doi.org/10.4236/ojst.2018.81001

Received: November 10, 2017

Accepted: January 9, 2018

Published: January 12, 2018

Copyright ( $\odot 2018$ by authors and Scientific Research Publishing Inc. This work is licensed under the Creative Commons Attribution International License (CC BY 4.0).

http://creativecommons.org/licenses/by/4.0/

\section{cC) (i) Open Access}

\begin{abstract}
Purpose: The study was performed to evaluate variability in nasopalatine canal using cone beam computed tomography (CBCT) in relation to age and gender. The study also provides an insight while considering anterior maxillary implants. Materials and Methods: The study included 200 subjects aged between 19 and 67 years who were divided into the following 3 groups: 1) 19 34 years old; 2) 35 - 49 years old; 3) $>50$ years old. The male and female subjects were 104 and 96 respectively. After obtaining a prior consent, CBCT was performed using a standard exposure and patient positioning protocol. The CBCT volume was sliced in three planes (X, Y, and Z) and was sequentially analyzed for the location, morphology and morphometric dimensions of the nasopalatine canal. The correlation of age and gender with all the variables were evaluated. Results: The present study revealed statistically significant differences in the length of the nasopalatine canal based on the age group. The slanted and the cylindrical variety of the nasopalatine canal were commonly observed in the study. However, no statistical differences were noted in the other variables such as number of openings at the nasal fossa, diameter of the incisive fossa, angulation of the canal as viewed in the sagittal sections and antero-posterior dimensions of the canal in the sagittal sections. Conclusion: The present study demonstrates the variability observed in the anatomy and morphology of the nasopalatine canal which is an important landmark for placing dental implants in the anterior maxillary region.
\end{abstract}

\section{Keywords}

Cone-Beam Computed Tomography, Nasopalatine Canal, Dental Implants

\section{Introduction}

The nasopalatine canal (NPC) origins at a point situated towards the anterior 
aspect of the floor of each nasal cavity. Each canal opens into the midline incisive foramen situated on the median plane of the palatine process of the maxilla, posterior to the central incisor and transmits the terminal branch of the descending nasopalatine artery, nasopalatine nerve, branches of the maxillary division of the trigeminal nerve and the maxillary artery [1]. The nasopalatine canal has been well-known as an important landmark for the implant surgeon [2]. To avoid disturbing the neurovascular bundles and cause any complications both during the operatory and post-operatory, the dimensional variability should be taken into account when dealing with surgical procedures such as implant placement in the central incisor region [3]. In the present study, cone beam computed tomography (CBCT) scans were used to assess the dimensions and morphology of the NPC.

The anterior maxilla is frequently traumatized and oral rehabilitation with osseointegrated dental implants is often the treatment of choice. The oral opening of the NPC, the incisive foramen, is found in this region which maintains close proximity to the roots of the upper central incisors [4] [5]. In view of this anatomical relationship, thorough radiographic analysis is necessary during dental implant planning [5] [6].

Therefore, knowledge of anatomical variations in the size, shape and number of the NPC is important, but studies on this topic are sparse [4] [7] [8] [9] [10].

Hence the present study aims to investigate the variability in nasopalatine canal using cone beam computed tomography in relation to age and gender.

\section{Materials and Method}

The present study included 200 CBCT images that included the entire NPC in all three planes. The source of data for the study was patients that reported to the Department of Oral Medicine and Radiology from January 2017 to September 2017. The СВСТ had been advised for evaluation of teeth in the anterior maxilla for various diagnostic purposes. The patients were informed about the study and informed consent was obtained. The CBCT scans from the patients with nasopalatine canal pathology (e.g. Nasopalatine duct cyst, tumor etc.), impacted teeth in the anterior maxilla, supernumerary teeth and trauma to the anterior maxilla were excluded from the study. Among the 200 patients, 104 were males and 96 were females. The patients were divided into 3 groups based on the age group I (19 - 34 years), group II (35 - 49 years) and group III (50 years and above) (Table 1). The CBCT scans were done using Hyperion X9 digital imaging system (Myray, Italy). The occlusal plane was positioned horizontally and the mid-sagittal plane was centred. The images were obtained at 70 to $75 \mathrm{kV}, 8$ to 10 $\mathrm{mA}$, and 11 to $12.3 \mathrm{sec}$ exposure time. The field of view (FOV) size was $11 \mathrm{~mm} \mathrm{X}$ $8 \mathrm{~mm}$ with a $300-\mu \mathrm{m}$ image resolution. The acquired volumes were reformatted to images of a thickness of $300 \mu \mathrm{m}$. For evaluation of the CBCT scans, a 21-inch LCD monitor's (HP L1910, Hewlett-Packard Development Co., Palo Alto, CA, USA) with $1280 \times 1024$ pixel. The NNT Imaging Software (v4.6) Windows 
Table 1. Sample distribution based on age group.

\begin{tabular}{cccccc}
\hline & & \multicolumn{3}{c}{ Openining at nasal fossa } & Percentage \\
\cline { 3 - 5 } & & 1 & 2 & 3 & Distribution \\
\hline \multirow{3}{*}{ Age group } & Group I & 85 & 36 & 13 & $67 \%$ \\
& Group II & 27 & 20 & 7 & $27 \%$ \\
& Group III & 7 & 2 & 3 & $6 \%$ \\
\multicolumn{2}{c}{ Petal } & 119 & 58 & 23 & $100 \%$ \\
\hline
\end{tabular}

edition (Myray, Italy) was used. The volume of the CBCT scans was sliced in three dimensions. Planes on the three axes (X, Y, and $\mathrm{Z}$ ) of the CBCT images were sequentially analyzed. The sections were reformatted in all the three axis to avoid discrepancy while measuring the canal dimensions. Two specialists in oral and maxillofacial radiology independently analyzed all of the images for NPC for its shape, curvature, opening and canal dimension. In case of disagreement, the observers had to reach consensus. The medio-lateral diameter of the incisive fossa and the number of openings at the nasal fossa were evaluated in the axial sections, while the shape of the canal, curvature of the canal, angle of curvature, length of the canal, and antero-posterior diameters were assessed in the sagittal slices (Figures 1-4).

The number of openings at the nasal fosse was assessed in the axial sections (Figure 5) and 3D reconstructed image as seen in the bony window (Figure 6). The angulation of the nasopalatine canal was measured as the angle between the long axis of the NPC and the floor of the nasal cavity in reformatted sagittal section. The length of the NPC was measured along the long axis of the canal and the antero-posterior measurements of the NPC was measured at three different levels i.e. at the incisive foramen opening, at the middle level of the NPC and at the level of the nasal fossa (Figure 7).

\section{Results}

\subsection{Number of Openings at the Nasal Fossa}

In the present study, $60 \%$ of the subjects had one opening at the nasal fossa, while $29 \%$ and $11 \%$ had two and three opening at the nasal fossa respectively. The gender-wise and age-wise distribution of the number of openings at the nasal fossa is shown in the Table 2 and Table 3 . The mean medio-lateral diameter at the foramen of Stenson in males and females was 2.56 and $2.54 \mathrm{~mm}$ respectively. The greatest diameter was observed at the level of the nasal fossa. No Statistically significant differences among males and females and the different age groups with respect to the number of openings or average medio-lateral diameter of the foramen of Stenson were not observed in the present study (Table 4 and Table 5). 


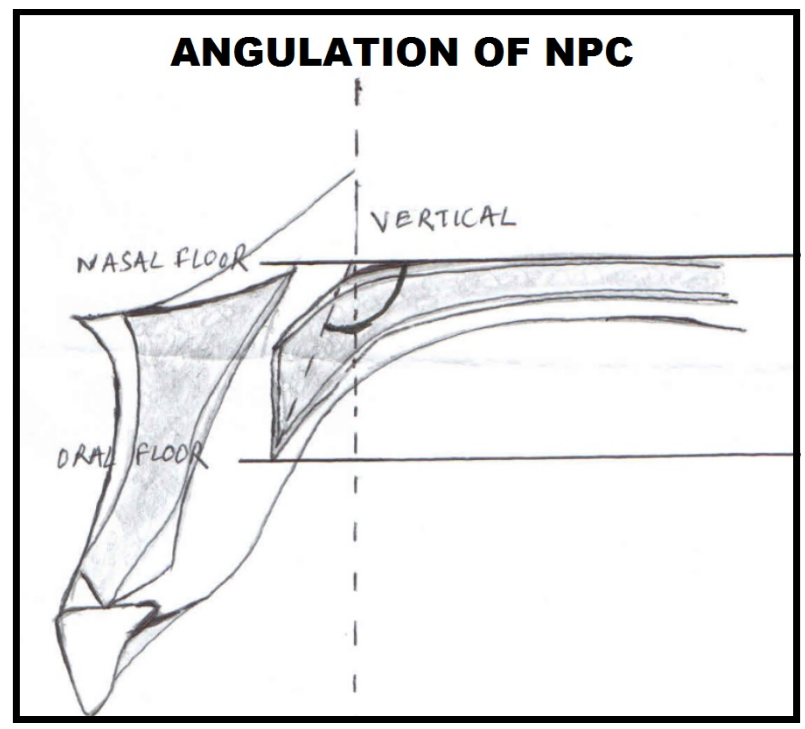

Figure 1. Line diagram to measure the angulation of the NPC.

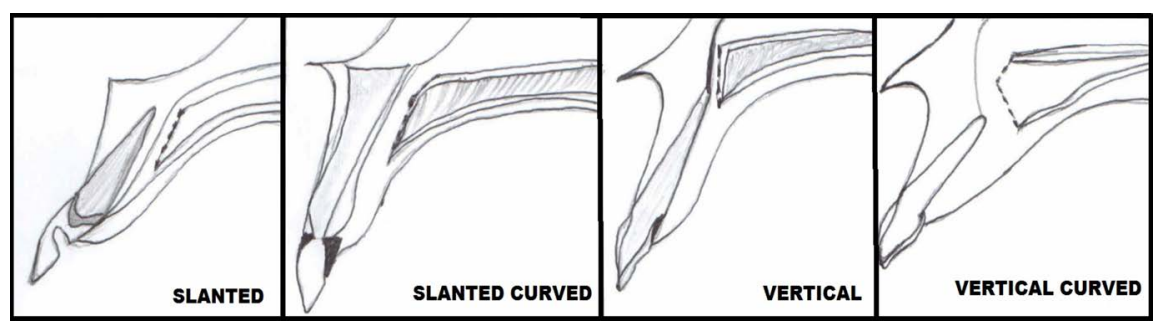

Figure 2. Line diagram to assess the curvature of the NPC.

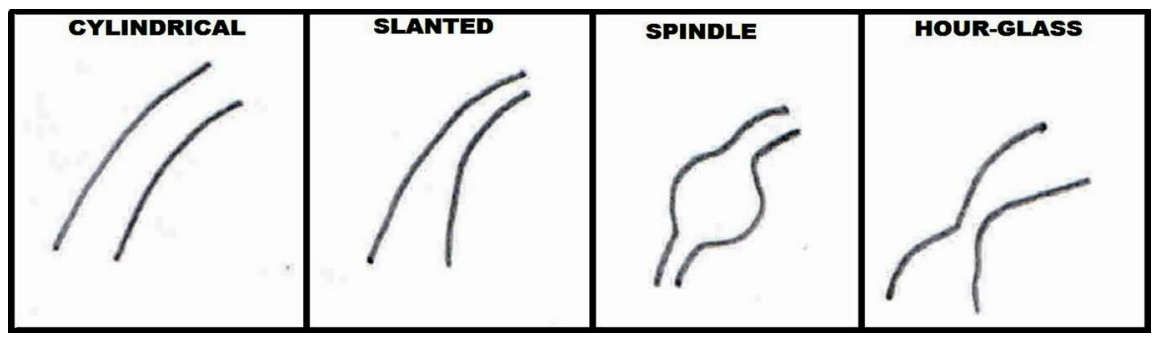

Figure 3. Line diagram to assess the shape of the NPC.

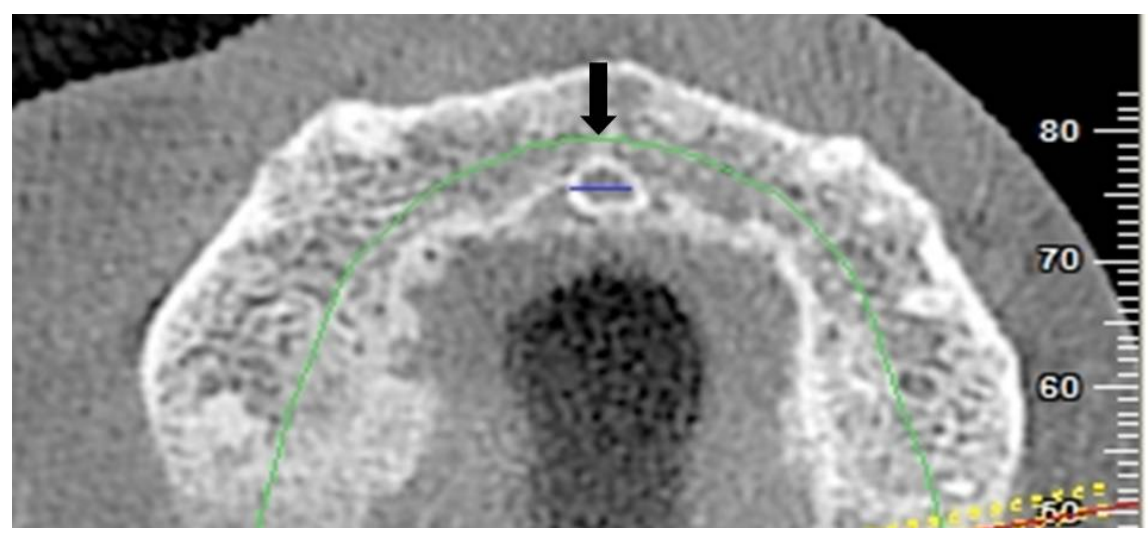

Figure 4. Mesio-distal diameter of the incisive fossa in axial view. 


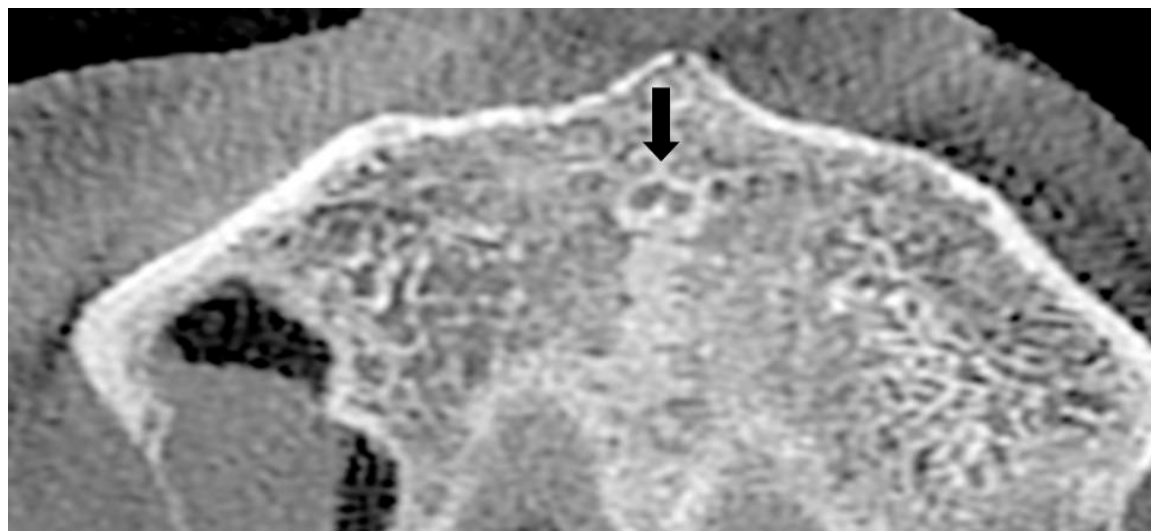

Figure 5. Foramen of Stenson viewed in the axial section at the level of the nasal floor.

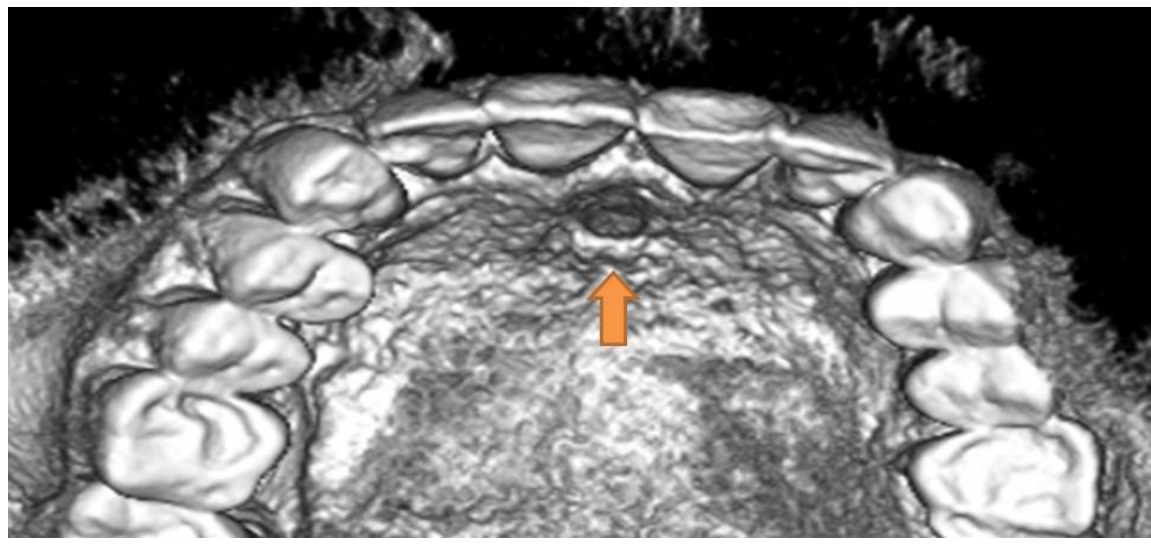

Figure 6. 3D Reconstructed image of the maxilla showing the incisive foramen.

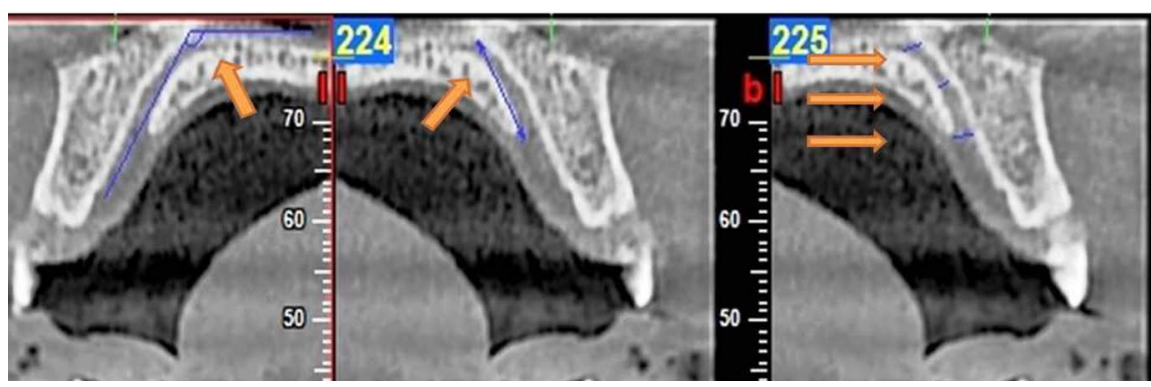

Figure 7. Linear morphometric measurements of the NPC in sagittal section. The Angulation of NPC; The length of NPC; The antero-posterior measurement of the NPC at three different levels.

Table 2. Opening of NPC at level of nasal fossa based on age group.

\begin{tabular}{cccccc}
\hline & & \multicolumn{3}{c}{ Openining at nasal fossa } & Percentage \\
\cline { 3 - 5 } & & 1 & 2 & 3 & Distribution \\
\hline \multirow{3}{*}{ Gender } & Male & 60 & 32 & 12 & $52 \%$ \\
& Female & 59 & 26 & 11 & $48 \%$ \\
& \multirow{2}{*}{ Total } & 119 & 58 & 23 & $100 \%$ \\
& & $59.5 \%$ & $29 \%$ & $11.5 \%$ & \\
\hline
\end{tabular}


Table 3. Openingof the NPC at level of nasal fossa based on gender.

\begin{tabular}{cccccc}
\hline & & \multicolumn{3}{c}{ Openining at nasal fossa } & Percentage \\
\cline { 3 - 5 } & & 1 & 2 & 3 & Distribution \\
\hline \multirow{3}{*}{ Gender } & Male & 60 & 32 & 12 & $52 \%$ \\
& Female & 59 & 26 & 11 & $48 \%$ \\
& \multirow{2}{*}{ Total } & 119 & 58 & 23 & $100 \%$ \\
& & $59.5 \%$ & $29 \%$ & $11.5 \%$ & \\
\hline
\end{tabular}

Table 4. Pearson's correlation test for comparison of all parameters according to age distribution ( ${ }^{\star}$ Significant difference among age group).

\begin{tabular}{|c|c|c|c|c|c|c|c|}
\hline \multicolumn{2}{|c|}{ Based on age group } & $\mathrm{N}$ & Mean & $\begin{array}{c}\text { Std. } \\
\text { Deviation }\end{array}$ & $\begin{array}{l}\text { Std. Error } \\
\text { Mean }\end{array}$ & $\mathrm{F}$ & $P$ value \\
\hline \multirow{3}{*}{$\begin{array}{l}\text { Mesio-distal diameter } \\
\text { of incisive fossa }\end{array}$} & Age group I & 134.00 & 2.51 & 1.09 & 0.09 & & \\
\hline & Age group II & 54.00 & 2.57 & 1.01 & 0.14 & .356 & .551 \\
\hline & Age group III & 12.00 & 3.00 & 1.10 & 0.32 & & \\
\hline \multirow{3}{*}{$\begin{array}{l}\text { Angulation of the NPC } \\
\text { to the Hard Palate }\end{array}$} & Age group I & 134.00 & 113.02 & 7.41 & 0.64 & & \\
\hline & Age group II & 54.00 & 111.32 & 7.49 & 1.02 & .191 & .662 \\
\hline & Age group III & 12.00 & 112.30 & 6.87 & 1.98 & & \\
\hline \multirow{3}{*}{ Length of NPC } & Age group I & 134.00 & 10.16 & 2.20 & 0.19 & & \\
\hline & Age group II & 54.00 & 10.29 & 2.49 & 0.34 & 38.241 & $.000^{*}$ \\
\hline & Age group III & 12.00 & 15.82 & 20.91 & 6.04 & & \\
\hline \multirow{3}{*}{$\begin{array}{c}\text { Anteroposterior width } \\
\text { of the NPC at the Nasal } \\
\text { Fossa Level }\end{array}$} & Age group I & 134.00 & 1.97 & 0.76 & 0.07 & & \\
\hline & Age group II & 54.00 & 2.04 & 0.78 & 0.11 & .718 & .398 \\
\hline & Age group III & 12.00 & 2.10 & 0.92 & 0.27 & & \\
\hline \multirow{3}{*}{$\begin{array}{c}\text { Anteroposterior width } \\
\text { of the NPC at Mid } \\
\text { Level }\end{array}$} & Age group I & 134.00 & 1.64 & 0.87 & 0.08 & & \\
\hline & Age group II & 54.00 & 1.64 & 0.80 & 0.11 & .365 & .547 \\
\hline & Age group III & 12.00 & 1.68 & 1.02 & 0.30 & & \\
\hline \multirow{3}{*}{$\begin{array}{c}\text { Anteroposterior width } \\
\text { of the NPC at Incisive } \\
\text { Foramen Level }\end{array}$} & Age group I & 134.00 & 1.54 & 1.28 & 0.11 & & \\
\hline & Age group II & 54.00 & 1.46 & 1.05 & 0.14 & 1.442 & .232 \\
\hline & Age group III & 12.00 & 1.88 & 1.79 & 0.52 & & \\
\hline
\end{tabular}

\subsection{Classification of the NPC According to Its Shape and Curvature}

The shape, direction, and course of the NPC were observed in sagittal sections and were classified into 4 categories according to their shape [7]: cylindrical, funnel, spindle, or hourglass. In the present study, cylindrical shape was the commonest $(47 \%)$ followed by funnel shape $(42 \%)$, hourglass shape $(7 \%)$ and spindle shape (4\%) respectively (Table 6 and Table 7). The NPCs were further classified according to their direction and course. The nasal floor was regarded as the "horizontal" plane and a perpendicular was drawn to this plane. The canal whose course changed by $>10^{\circ}$ from the vertical were regarded to be "slanted", 
Table 5. Karl Pearson's correlation test for comparison of all parameters between males and females.

\begin{tabular}{|c|c|c|c|c|c|c|}
\hline Based on $\mathrm{Ge}$ & der & Mean & Std. Deviation & Std. Error Mean & $\mathrm{t}$ value & $P$ value \\
\hline Mesio-distal & Male & 2.56 & 1.03 & 0.10 & & \\
\hline $\begin{array}{l}\text { diameter of } \\
\text { incisive fossa }\end{array}$ & Female & 2.54 & 1.11 & 0.11 & 0.15 & 0.73 \\
\hline Angulation of the & Male & 112.34 & 7.68 & 0.75 & & \\
\hline NPC to the Hard & & & & & -0.35 & 0.59 \\
\hline Palate & Female & 112.71 & 7.12 & 0.73 & & \\
\hline & Male & 10.33 & 2.19 & 0.21 & & \\
\hline Length of NPC & Female & 10.75 & 7.71 & 0.79 & -0.53 & 0.13 \\
\hline Anteroposterior & Male & 1.96 & 0.77 & 0.08 & & \\
\hline $\begin{array}{c}\text { width of the NPC } \\
\text { at the Nasal Fossa } \\
\text { Level }\end{array}$ & Female & 2.02 & 0.78 & 0.08 & -1.15 & 0.79 \\
\hline Anteroposterior & Male & 1.58 & 0.83 & 0.08 & & \\
\hline $\begin{array}{l}\text { width of the NPC } \\
\text { at Mid Level }\end{array}$ & Female & 1.72 & 0.88 & 0.09 & 0.198 & 0.92 \\
\hline $\begin{array}{l}\text { Anteroposterior } \\
\text { width of the NPC }\end{array}$ & Male & 1.41 & 1.19 & 0.12 & & \\
\hline $\begin{array}{l}\text { at Incisive } \\
\text { Foramen Level }\end{array}$ & Female & 1.67 & 1.31 & 0.13 & 0.19 & 0.29 \\
\hline
\end{tabular}

Table 6. Shape of the NPC based on age group.

\begin{tabular}{|c|c|c|c|c|c|c|c|}
\hline & & \multicolumn{4}{|c|}{ Shape of NPC } & \multirow{2}{*}{ Total } & \multirow{2}{*}{$\mathrm{p}$ value } \\
\hline & & Cylinderical & Funnel & Hourglass & Spindle & & \\
\hline \multirow{3}{*}{$\begin{array}{l}\text { Age } \\
\text { group }\end{array}$} & Group I & 62 & 58 & 8 & 6 & 134 & \multirow{5}{*}{0.987} \\
\hline & Group II & 25 & 22 & 4 & 3 & 54 & \\
\hline & Group III & 6 & 5 & 1 & 0 & 12 & \\
\hline & Total & 93 & 85 & 13 & 9 & 200 & \\
\hline $\begin{array}{l}\mathrm{Pe} \\
\mathrm{dis}\end{array}$ & $\begin{array}{l}\text { centage } \\
\text { ribution }\end{array}$ & $46.5 \%$ & $42.5 \%$ & $6.5 \%$ & $4.5 \%$ & $100 \%$ & \\
\hline
\end{tabular}

Table 7. Shape of the NPC based on gender.

\begin{tabular}{cccccccc}
\hline & \multicolumn{5}{c}{ Shape of NPC } & \multirow{2}{*}{ Total } & p value \\
\cline { 2 - 5 } & Male & 48 & 45 & 7 & 4 & 104 & \\
\hline \multirow{2}{*}{ Gender } & Female & 45 & 40 & 6 & 5 & 96 & 0.96 \\
Total & 93 & 85 & 13 & 9 & 200 & \\
$\begin{array}{c}\text { Percentage } \\
\text { distribution }\end{array}$ & $46.5 \%$ & $42.5 \%$ & $6.5 \%$ & $4.5 \%$ & $100 \%$ & \\
\hline
\end{tabular}

and those whose course changed by $<10^{\circ}$ from vertical were regarded as "vertical". Based on this, four types of NPCs curvature were noted: vertical, verticalcurved, slanted, and slanted curved. The slanted type of NPCs was the commonest $(73 \%)$, followed by slanted curved (21\%), vertical (4\%) and vertical curved 
(2\%) respectively (Table 8 and Table 9). Statistically significant differences between the genders and between the different age groups with respect to the shape and curvature of the NPC were not observed (Table 4 and Table 5) (Graphs 1-4).

Table 8. Curvature of the NPC based on age group.

\begin{tabular}{|c|c|c|c|c|c|c|c|}
\hline & & \multicolumn{4}{|c|}{ Curvature of NPC } & \multirow[b]{2}{*}{ Total } & \multirow[b]{2}{*}{$\mathrm{p}$ value } \\
\hline & & Slanted & $\begin{array}{l}\text { Slanted } \\
\text { Curved }\end{array}$ & Vertical & $\begin{array}{l}\text { Vertical } \\
\text { Curved }\end{array}$ & & \\
\hline \multirow{3}{*}{ Age group } & Group I & 95 & 31 & 7 & 1 & 134 & \multirow{4}{*}{0.214} \\
\hline & Group II & 40 & 10 & 1 & 3 & 54 & \\
\hline & Group III & 11 & 1 & 0 & 0 & 12 & \\
\hline \multicolumn{2}{|c|}{ Total } & 146 & 42 & 8 & 4 & 200 & \\
\hline \multicolumn{2}{|c|}{ Percentage distribution } & $73 \%$ & $21 \%$ & $4 \%$ & $2 \%$ & $100 \%$ & \\
\hline
\end{tabular}

Table 9. Curvature of the NPC based on gender.

\begin{tabular}{|c|c|c|c|c|c|c|c|}
\hline & & \multicolumn{4}{|c|}{ Curvature of NPC } & \multirow[b]{2}{*}{ Total } & \multirow[b]{2}{*}{$\mathrm{p}$ value } \\
\hline & & Slanted & $\begin{array}{l}\text { Slanted } \\
\text { Curved }\end{array}$ & Vertical & $\begin{array}{l}\text { Vertical } \\
\text { Curved }\end{array}$ & & \\
\hline \multirow{2}{*}{ Gender } & Male & 74 & 23 & 4 & 3 & 104 & \\
\hline & Female & 72 & 19 & 4 & 1 & 96 & 0.779 \\
\hline \multicolumn{2}{|c|}{ Total } & 146 & 42 & 8 & 4 & 200 & \\
\hline \multicolumn{2}{|c|}{ Percentage distribution } & $73 \%$ & $21 \%$ & $4 \%$ & $2 \%$ & $100 \%$ & \\
\hline
\end{tabular}

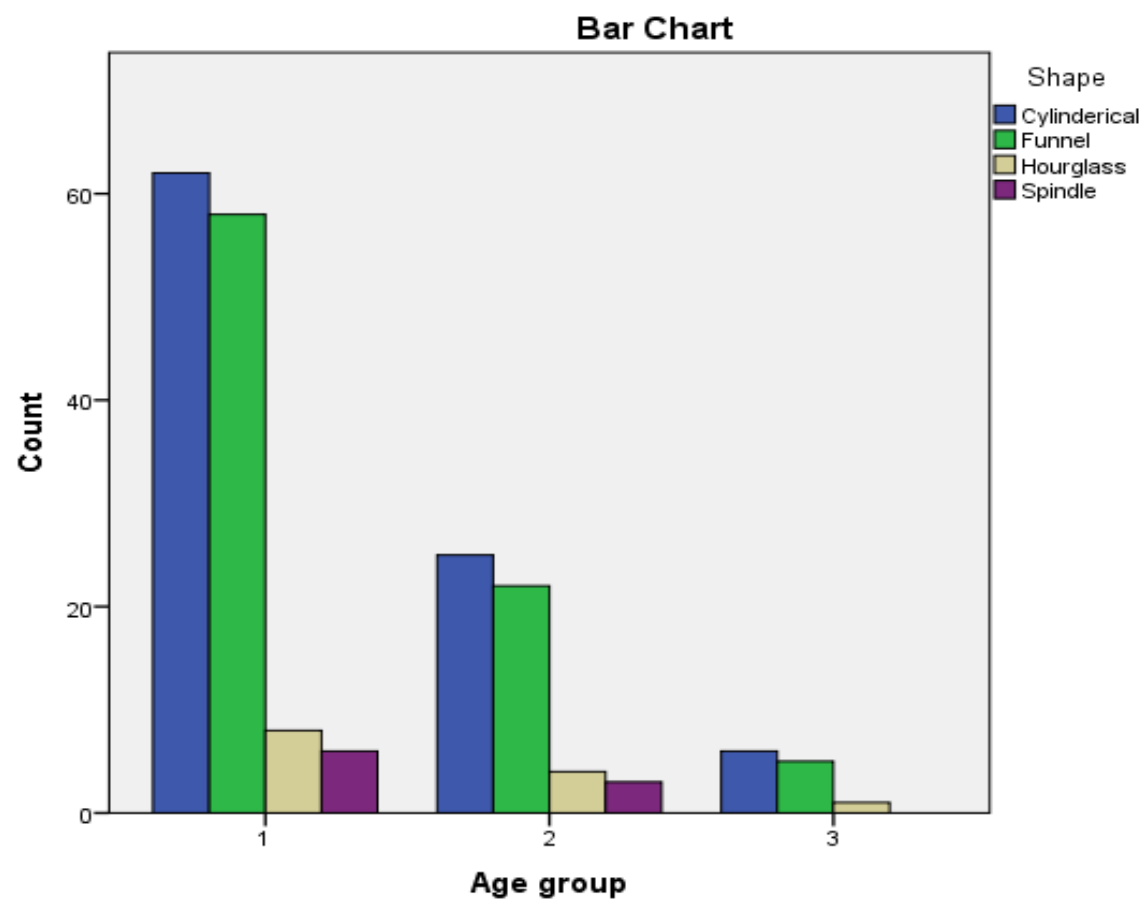

Graph 1. Shape of the NPC based on age group. 


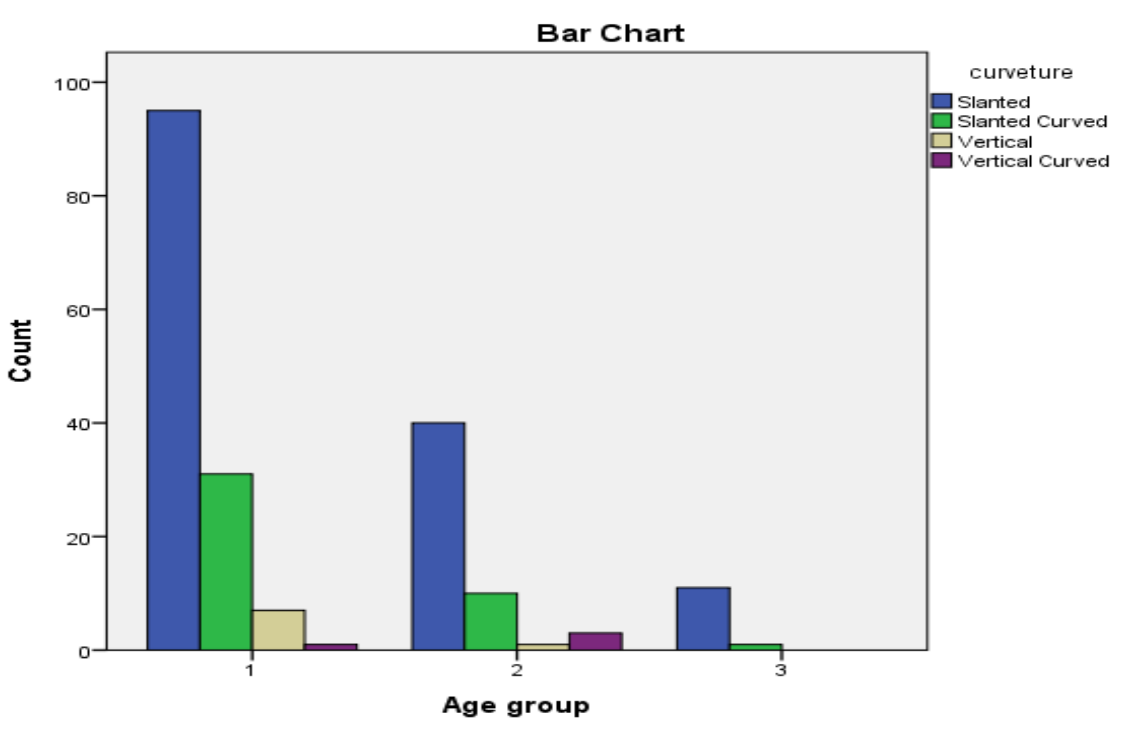

Graph 2. Curvature of the NPC based on age group.

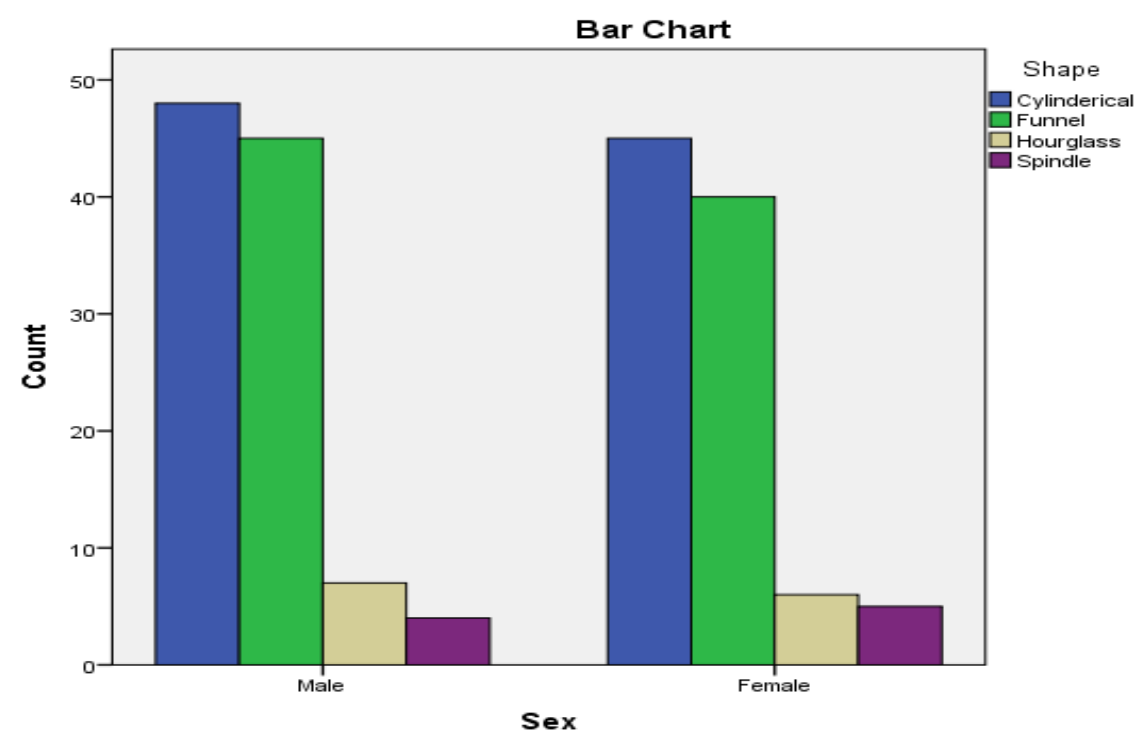

Graph 3. Shape of the NPC based on gender.

\subsection{Angulation of the NPC}

Angulation of the NPC was measured as the angle between the floor of the nasal fossa and long axis of the NPC. The mean angulation in males and females were 112.34 and 112.71 respectively. As all the subjects had an obtuse angle which suggested that the incisive foramen was located anterior to the nasopalatine foramina. Statistical analysis failed to show the correlation of the slanting angle of the NPC with age or gender (Table 4 and Table 5).

\subsection{Length of the NPC}

The length of NPC was measured in the sagittal section between the level of the nasal fossa and the level of the hard palate along the long axis of the canal. The 


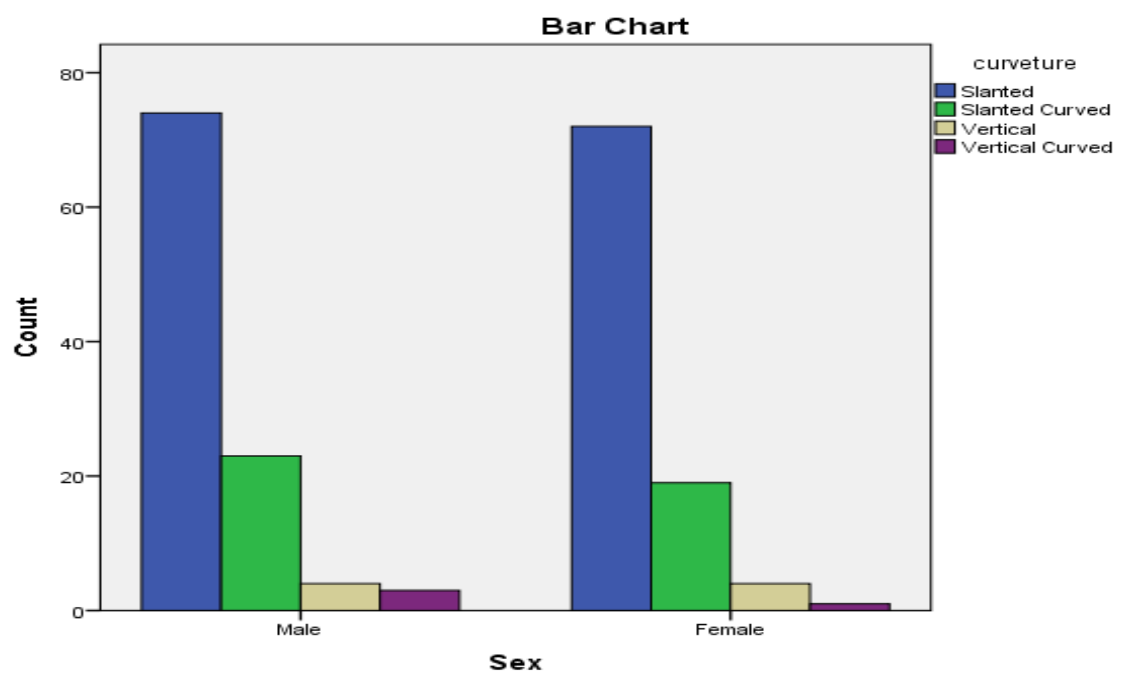

Graph 4. Curvature of the NPC based on gender.

mean length of NPC in males and females were 10.33 and $10.75 \mathrm{~mm}$ respectively. Statistical analysis failed to show the correlation of the length of NPC and the gender distribution. However, statistically significant differences in the length of the NPC were observed in different age groups $(\mathrm{p}=0.0001)$ (Table 4 and Table 5).

\subsection{Antero-Posterior Diameter of the Canal}

The antero-posterior diameter of the NPC as viewed in sagittal plane was measured at three different levels along the long axis of the canal. The diameter of the canal in males at nasal floor level, mid-level and incisive foramen level were 1.96 $\mathrm{mm}, 1.58 \mathrm{~mm}$ and $1.41 \mathrm{~mm}$ respectively. The diameter of the canal in females at nasal floor level, mid-level and incisive foramen level were $2.02 \mathrm{~mm}, 1.72 \mathrm{~mm}$ and $1.67 \mathrm{~mm}$ respectively. The differences in the values between males and females and among the different age groups were not found to be statistically significant (Table 4 and Table 5).

\section{Discussion}

In the present study up to three foramen were observed at the level of the nasal floor. Song et al. [11] and Jacob et al. [12] observed only two foramina in their studies. Mraiwa et al. [13] and Liang et al. [1] who also reported observing up to four foramina at the level of the nasal floor. Sicher [14] reported that there could be up to six separate foramen. The variability in results could be due to sample differences, age, ethnicity and the imaging techniques used in different studies.

In the present study, the average diameter of the incisive fossa in males was $2.56 \mathrm{~mm}$ and in females were $2.54 \mathrm{~mm}$ respectively. Kotaro et al. [15] in their study found out that the average mesiodistal diameter of the incisive fossa was $3.3 \mathrm{~mm}$ and $2.8 \mathrm{~mm}$ in males and females respectively. Matsumura et al. [16] in their study measured it as $3.1 \mathrm{~mm}$ and $3.3 \mathrm{~mm}$ in males and females respectively. 
In the present study, the average diameter of the canal at the level of the nasal floor was $1.54 \mathrm{~mm}$ and $1.50 \mathrm{~mm}$ in males and females respectively. Thakur et al. [7] in their study measured the average diameter of the canal at the level of the nasal floor to be $1.74 \mathrm{~mm}$ and $1.76 \mathrm{~mm}$ in males and females respectively. The mesiodistal diameter of the incisve foramen was more in males than in females which is in accordance the previous studies. The difference in the values could be attributed to the population chosen and the imaging modality used in the study.

In the present study the average length of the NPC in sagittal plane was 10.33 $\mathrm{mm}$ and $10.75 \mathrm{~mm}$ in males and females respectively. Naseeh et al. [17] in their study measured the average length of the NPC in sagittal plane to be $12.80 \mathrm{~mm}$ and $10.88 \mathrm{~mm}$ in males and females respectively. While Thakur et al. [7] measured it to be $10.96 \mathrm{~mm}$ and $9.20 \mathrm{~mm}$ in males and females respectively. In the present study the angulation of the NPC from the hard palate was 112.34 and 112.71 in males and females respectively. Panjnoush et al. [18] in their study measured the angulation of the NPC from the hard palate to be 109.3 and 109.7 in males and females respectively. Gonul et al. [19] measured it as 107.74 and 107.33 in males and females respectively.

In accordance to the previous studies, cylindrically shaped NPC was most commonly observed which was also found in most of our subjects [1] [20]. Song et al. [11] reported the predominance of the vertical type of NPC in their study, however in our study, slanted canals were more commonly observed than vertical ones.

In this study, the average length of the NPC was $10.16 \mathrm{~mm}$ in age group I, $10.29 \mathrm{~mm}$ in age group II and $15.82 \mathrm{~mm}$ in Age group III respectively. Statistically significant difference was observed in the measurement of length of the NPC. No statistical difference was observed in other parameters among the different age groups. This could be attributed to the dentulous and the edentulous population chosen in this study. There might be an increase in the size of the NPC, as observed in other studies [1] [20] could be due to the edentulous status of the patient rather than a age-related change. Table 10 illustrates the comparative analysis of the morphometric measurements of NPC performed by different researchers in comparison to that of the present study.

The technique of implant placement directly in the nasopalatine canal was first described by Scher in 1994 [24] and later by Misch [25] in 1999. Artzi et al. successfully treated a patient with an implant in the nasopalatine canal by adapting a corticocancellous bone block graft to the canal causing displacement of the neurovascular bundle posteriorly [26].

Penarrocha et al. [27] conducted a retrospective study with a long follow up in patients rehabilitated with implants in NPC in severe atrophic maxilla. A total of 13 implants were placed in the NPC with $84.6 \%$ success rate till 70 months follow up.

The difference in parameters from the previously reported studies could be 
Table 10. Gender comparison of morphometric measurements of NPC in previous studies. (* Significant difference among males and females).

\begin{tabular}{|c|c|c|c|c|c|}
\hline Author & $\begin{array}{c}\text { Number of } \\
\text { patients Imaging } \\
\text { modality }\end{array}$ & Nasopalatine canal length & $\begin{array}{c}\text { Angulation of NPC to } \\
\text { hard palate }\end{array}$ & $\begin{array}{c}\text { Mesiodistal diameter } \\
\text { of Incisive } \\
\text { foramen }\end{array}$ & $\begin{array}{l}\text { Mesiodistal diameter of } \\
\text { nasopalatine foramen at } \\
\text { the level of nasal floor }\end{array}$ \\
\hline \multirow{2}{*}{$\begin{array}{c}\text { Thakur et al. } \\
\text { [7] } \\
\text { (INDIA) }\end{array}$} & 100 & M: $10.96 \pm 1.99$ & M: $115.54 \pm 9.44$ & M: $3.47 \pm 0.89$ & M: $1.74 \pm 0.62$ \\
\hline & СBCT & F: $9.20 \pm 2.16$ & $\mathrm{~F}: 118.24 \pm 6.10$ & F: $3.76 \pm 0.97$ & $\mathrm{~F}: 1.76 \pm 0.90$ \\
\hline \multirow{2}{*}{$\begin{array}{l}\text { Gonul et al. [19] } \\
\text { (TURKEY) }\end{array}$} & 100 & $M: 13.68 \pm 2.73^{*}$ & M: $107.74 \pm 13.56$ & M: $6.68 \pm 2.64$ & M: $3.72 \pm 1.41$ \\
\hline & MDCT & $F: 11.43 \pm 2.78^{*}$ & F: $107.33 \pm 11.96$ & $F: 5.83 \pm 2.62$ & $\mathrm{~F}: 3.07 \pm 1.34$ \\
\hline \multirow{2}{*}{$\begin{array}{l}\text { Fernández-Alonso } \\
\text { A et al. }[21] \\
\text { (SPAIN) }\end{array}$} & 224 & $M: 13.16 \pm 2.72^{*}$ & & M: 3.791 .38 & \\
\hline & $\mathrm{CBCT}$ & F: $11.58 \pm 2.64^{*}$ & & F: 3.421 .06 & \\
\hline \multirow{2}{*}{$\begin{array}{l}\text { Friedrich et al. [22] } \\
\text { (GERMANY) }\end{array}$} & 200 & $M: 12.02 \pm 3.01^{*}$ & & M: $4.96 \pm 1.90^{*}$ & M: $3.57 \pm 1.56$ \\
\hline & СBCT & F: $10.18 \pm 2.37^{*}$ & & F: $3.96 \pm 1.29^{*}$ & $\mathrm{~F}: 3.27 \pm 1.49$ \\
\hline \multirow{2}{*}{$\begin{array}{l}\text { Mohammed et al. [23] } \\
\text { (IRAQ) }\end{array}$} & 110 & $M: 13.83 \pm 3.1^{*}$ & & $M: 4.65 \pm 2.16^{*}$ & $M: 2.47 \pm 0.52^{*}$ \\
\hline & СBCT & F: $12.44 \pm 2.0^{*}$ & & F: $3.57 \pm 1.21^{*}$ & F: $2.73 \pm 0.71^{*}$ \\
\hline \multirow{2}{*}{$\begin{array}{l}\text { Ito et al. }[15] \\
\text { (JAPAN) }\end{array}$} & 122 & & & M: $3.3 \pm 0.9$ & M: $3.4 \pm 1.1$ \\
\hline & MDCT & & & F: $2.8 \pm 0.9$ & F: $2.9 \pm 1.1$ \\
\hline \multirow{2}{*}{$\begin{array}{l}\text { Panjnoush et al. [18] } \\
\text { (IRAN) }\end{array}$} & 300 & M: $14.4 \pm 3.00$ & M: $109.3 \pm 5.6$ & $\mathrm{M}: 4.92 \pm 1.25^{*}$ & \\
\hline & $\mathrm{CBCT}$ & $\mathrm{F}: 13.8 \pm 3.0$ & F: $109.7 \pm 5.8$ & $F: 4.49 \pm 0.9^{*}$ & \\
\hline \multirow{2}{*}{$\begin{array}{c}\text { Matsumura et al. }[16] \\
\text { (JAPAN) }\end{array}$} & 93 & $M: 13.8 \pm 2.2^{*}$ & M: $105.5 \pm 8.6^{*}$ & M: $3.1 \pm 1.4$ & \\
\hline & CBCT & F: $12.2 \pm 2.3^{*}$ & F: $109.6 \pm 7.9^{*}$ & F: $3.3 \pm 1.2$ & \\
\hline \multirow{2}{*}{$\begin{array}{l}\text { Naseeh et al. [17] } \\
\text { (LEBANON) }\end{array}$} & 63 & $\mathrm{M}: 12.80 \pm 2.45$ & M: $17.80 \pm 8.87$ & M: $5.25 \pm 0.96$ & \\
\hline & CBCT & F: $10.88 \pm 2.53$ & F: $16.74 \pm 7.77$ & F: $4.74 \pm 1.18$ & \\
\hline \multirow{2}{*}{$\begin{array}{l}\text { Present Study } \\
\text { (INDIA) }\end{array}$} & 200 & M: $10.33 \pm 2.19$ & M: $112.34 \pm 7.68$ & M: $2.56 \pm 1.03$ & M: $1.54 \pm 0.70$ \\
\hline & СBCT & F: $10.75 \pm 7.71$ & F: $112.71 \pm 7.12$ & $\mathrm{~F}: 2.54 \pm 1.11$ & $F: 1.50 \pm 0.70$ \\
\hline
\end{tabular}

due to population variation, race, ethnicity, imaging modality used and observer variability. Nevertheless, the anatomic variations in morphological parameters were significant, emphasizing the role of CBCT in assessment of NPC in treatment planning for implant placement, pathologies in this region or in preventing not premeditated complications while operating in the anterior maxillary region. The curvature, shape, angulation of the canal and its dimensions are the most significant parameters for placement of implants in the maxillary incisor region. Also, the number of openings, medio-lateral dimensions of the incisive fossa and length of the canal may prove important when implants within and around the nasopalatine canal are being planned.

However there were few limitations in the present study, the variability of the NPC was not assessed in the patients having any trauma to the anterior maxillary region. The patients who had been already treated with fixed prosthesis (dental implants and porcelain fused to metal crowns) in the anterior maxillary region were ruled out from the present study because the streaking artefacts would hinder the measurements of the NPC. 


\section{Conclusion}

In conclusion, this study highlights the anatomic variability and the radiomorphometric measurements of the NPC. These anatomic variations can only be assessed using 3D imaging modalities. The assessment of this anatomical landmark in treatment planning of this area for implant placement or assessment of pathologies in this region is of utmost importance. The shape, curvature and angulation of the canal are the most significant parameters for placement of implants in the maxillary incisor region. Additionally, the number of openings, medio-lateral dimensions, length of the canal, and level of its division may prove important when implants within the nasopalatine canal are being considered.

\section{References}

[1] Liang, X., Jacobs, R., Martens, W., et al. (2009) Macro- and Microanatomical, Histological and Computed Tomography Scan Characterization of the Nasopalatine canal. Journal of Clinical Periodontology, 36, 598-603. https://doi.org/10.1111/j.1600-051X.2009.01429.x

[2] Greenstein, G., Cavallaro, J. and Tarnow, D. (2008) Practical Application of Anatomy for the Dental Implant Surgeon. Journal of Periodontology, 79, 1833-1846. https://doi.org/10.1902/jop.2008.080086

[3] Jacobs, R., Lambrichts, I., Liang, X., et al. (2007) Neurovascularization of the Anterior Jaw Bones Revisited Using High-Resolution Magnetic Resonance Imaging. Oral Surgery, Oral Medicine, Oral Pathology, Oral Radiology, and Endodontology, 103, 683-693. https://doi.org/10.1016/j.tripleo.2006.11.014

[4] Al-Amery, S.M., Nambiar, P., Jamaludin, M., John, J. and Ngeow, W.C. (2015) Cone Beam Computed Tomography Assessment of the Maxillary Incisive Canal and Foramen: Considerations of Anatomical Variations When Placing Immediate Implants. PLoS One, 10, Article ID: e0117251. https://doi.org/10.1371/journal.pone.0117251

[5] Bornstein, M.M., Balsiger, R., Sendi, P. and Von Arx, T. (2011) Morphology of the Nasopalatine Canal and Dental Implant Surgery: A Radiographic Analysis of 100 Consecutive Patients Using Limited Conebeam Computed Tomography. Clinical Oral Implants Research, 22, 295-301. https://doi.org/10.1111/j.1600-0501.2010.02010.x

[6] Acar, B. and Kamburoglu, K. (2015) Morphological and Volumetric Evaluation of the Nasopalatinal Canal in a Turkish Population Using Cone-Beam Computed Tomography. Surgical and Radiologic Anatomy, 37, 259-265.

[7] Thakur, A.R., Burde, K., Guttal, K. and Naikmasur, V.G. (2013) Anatomy and Morphology of the Nasopalatine Canal Using Cone-Beam Computed Tomography. Imaging Science in Dentistry, 43, 273-281. https://doi.org/10.5624/isd.2013.43.4.273

[8] Kajan, Z.D., Kia, J., Motevasseli, S. and Rezaian, S.R. (2015) Evaluation of the Nasopalatine Canal with Conebeam Computed Tomography in an Iranian Population. Journal of Dental Research (Isfahan), 12, 14-19. https://doi.org/10.4103/1735-3327.150289

[9] Lopez Jornet, P., Boix, P., Sanchez Perez, A. and Boracchia, A. (2015) Morphological Characterization of the Anterior Palatine Region Using Cone Beam Computed Tomography. Clinical Implant Dentistry and Related Research, 17, e459-e464. https://doi.org/10.1111/cid.12271 
[10] Etoz, M. and Sisman, Y. (2014) Evaluation of the Nasopalatine Canal and Variations with Conebeam Computed Tomography. Surgical and Radiologic Anatomy, 36, 805-812. https://doi.org/10.1007/s00276-014-1259-9

[11] Song, W.C., Jo, D., Lee, J.Y., Kim, J.N., Hur, M.S., Hu, K.S., et al. (2009) Microanatomy of the Incisive Canal Using Three-Dimensional Reconstruction of MicroCT Images: an ex vivo Study. Oral Surgery, Oral Medicine, Oral Pathology, Oral Radiology, and Endodontology, 108, 583-590. https://doi.org/10.1016/j.tripleo.2009.06.036

[12] Jacob, S., Zelano, B., Gungor, A., Abbott, D., Naclerio, R. and McClintock, M.K. (2000) Location and Gross Morphology of the Nasopalatine Duct in Human Adults. Archives of Otolaryngology - Head and Neck Surgery, 126, 741-748. https://doi.org/10.1001/archotol.126.6.741

[13] Mraiwa, N., Jacobs, R., Van Cleynenbreugel, J., Sanderink, G., Schutyser, F., Suetens, P., et al. (2004) The Nasopalatine Canal Revisited Using 2D and 3D CT Imaging. Dentomaxillofacial Radiology, 33, 396-402. https://doi.org/10.1259/dmfr/53801969

[14] Sicher, H. (1962) Anatomy and Oral Pathology. Oral Surgery, Oral Medicine, Oral Pathology, Oral Radiology, and Endodontology, 15, 1264-1269. https://doi.org/10.1016/0030-4220(62)90163-9

[15] Ito, K., Muramatsu, T., Kawashima, Y., Hirahara, N., Sakae, T., Okada, H. and Kaneda, T. (2016) Characteristic Image Findings of the Nasopalatine Duct Region Using Multidetector-Row CT. Journal of Hard Tissue Biology, 25, 69-74. https://doi.org/10.2485/jhtb.25.69

[16] Matsumura, T., Ishida, Y., Kawabe, A. and Ono, T. (2017) Quantitative Analysis of the Relationship between Maxillary Incisors and the Incisive Canal by Cone-Beam Computed Tomography in an Adult Japanese Population. Progress in Orthodontics, 18, 241-246. https://doi.org/10.1186/s40510-017-0181-1

[17] Nasseh, I., Aoun, G. and Sokhn, S. (2017) Assessment of the Nasopalatine Canal: An Anatomical Study. Acta Informatica Medica, 25, 34-38.

[18] Panjnoush, M., Norouzi, H., Kheirandish, Y., Shamshiri, A.R. and Mofidi, N. (2016) Evaluation of Morphology and Anatomical Measurement of Nasopalatine Canal using Cone Beam Computed Tomography. Journal of Dentistry, 13, 287-294.

[19] Gonul, Y., Bucak, A., Atalay, Y., Beker-Acay, M., Caliskan, A., Sakarya, G., et al. (2016) MDCT Evaluation of Nasopalatine Canal Morphometry and Variations: An Analysis of 100 Patients. Diagnostic and Interventional Imaging, 97, 1165-1172. https://doi.org/10.1016/j.diii.2015.11.012

[20] Mardinger, O., Namani-Sadan, N., Chaushu, G. and Schwartz-Arad, D. (2008) Morphologic Changes of the Nasopalatine Canal Related to Dental Implantation: A Radiologic Study in Different Degrees of Absorbed Maxillae. Journal of Periodontology, 79, 1659-1662. https://doi.org/10.1902/jop.2008.080043

[21] Fernández-Alonso, A., et al. (2015) Critical Anatomic Region of Nasopalatine Canal Based on Tridimensional Analysis: Cone Beam Computed Tomography. Scientific Reports, 5, Article No. 12568

[22] Friedrich, R.E., Laumann, F., Zrnc, T. and Assaf, A.T. (2015) The Nasopalatine Canal in Adults on Cone Beam Computed Tomograms-A Clinical Study and Review of the Literature. In Vivo, 29, 467-486.

[23] Mohammed, D.A. (2016) Anatomical Variation in the Dimension of Nasopalatine Canal on Cone Beam Computed Tomography CBCT Images among Sulaimani Population. Acta Medica International, 3, 82-87. 
https://doi.org/10.5530/ami.2016.2.18

[24] Scher, E.L. (1994) Use of the Incisive Canal as a Recipient Site for Root Form Implants: Preliminary Clinical Reports. Implant Dentistry, 3, 38-41. https://doi.org/10.1097/00008505-199404000-00007

[25] Misch, C. (1999) Premaxilla Implant Considerations: Treatment Planning and Surgery. In: Misch, C., Ed., Implant Dentistry, Mosby, St Louis, 509-519.

[26] Artzi, Z., Nemcovsky, C.E., Bitlitum, I. and Segal, P. (2000) Displacement of the Incisive Foramen in Conjunction with Implant Placement in the Anterior Maxilla without Jeopardizing Vitality of Nasopalatine Nerve and Vessels: A Novel Surgical Approach. Clinical Oral Implants Research, 11, 505-510. https://doi.org/10.1034/j.1600-0501.2000.011005505.x

[27] Penarrocha, D., Candel, E., Guirado, J.L.C., Canullo, L. and Penarrocha, M. (2014) Implants Placed in the Nasopalatine Canal to Rehabilitate Severely Atrophic Maxillae: A Retrospective Study with Long Follow-Up. Journal of Oral Implantology, 40, 699-706. https://doi.org/10.1563/AAID-JOI-D-12-00145 